\title{
Making Pittsburghese: Communication technology, expertise, and the discursive construction of a regional dialect
}

\author{
Barbara Johnstone \\ Carnegie Mellon University \\ bj4@andrew.cmu.edu \\ A slightly revised version of the paper has been published as \\ Johnstone, Barbara. 2011. Making Pittsburghese: Communication technology, expertise, \\ and the discursive construction of a regional dialect. Language sciences 31: 3-15.
}

Please refer to the article for page numbers and to make sure quotations are correct.

\begin{abstract}
This paper explores how changing technologies for broadcast communication shape the expertise that comes into play in the discursive construction of a regional dialect in public interaction that includes both institutionally-sanctioned experts like linguists and laypeople with other sources of expertise. Based on an analysis of discourse about Pittsburgh speech, or "Pittsburghese," in print newspapers, a website, an online discussion board, and a Wikipedia entry, it is argued that both scholars interested in the historical process of language-making and those interested in interaction with the public on the topic of non-standard varieties can benefit from thinking about the role of technology in determining whose voices are heard when.
\end{abstract}

\section{Key Words}

Dialect, Discourse, Expertise, Pittsburgh, Technology 


\section{Making Pittsburghese: Communication technology, expertise, and the discursive construction of a regional dialect ${ }^{1}$}

\section{Overview}

As many linguists and anthropologists have argued, languages are the products of culturally and historically situated, reflexive, ex post facto discourse about discourse (or talk, speech, "parole" or "languaging," as it is variously known). The same is of course true of dialects. Dialect boundaries are not inscribed on the landscape, so he world does not present itself to linguists with dialects waiting to be discovered. Just as languages are created in discourse, so are dialects. This paper explores the relationship between communication technology and expertise in the process of dialect-making. It asks how changing technologies for broadcast communication shape the expertise that comes into play when dialect-construction happens in public interaction. How is language expertise distributed, contested, and negotiated across media? How, and on what basis, are claims to expertise made? Under what technological conditions do linguists and other institutionally recognized experts get the floor in dialect-making discourse, and under what conditions do laypeople get the floor?

\footnotetext{
${ }^{1}$ The Pittsburgh Speech and Society Project was partially funded by U.S. National Science Foundation grants BCS-0417684 and BCS-0417657. Earlier versions of this paper were presented at the American Anthropological Association's Annual Meeting and at Sociolinguistics Symposium 17 in 2008, at the University of Pittsburgh Linguistics Colloquium in 2009, and at York University, Toronto, in 2010. I am grateful to audiences at all those gatherings. I am also grateful to Andrew E. Danielson for bringing the newspaper articles to my attention and for his help in analyzing them, to Patricia Parslow for talking to me about her late husband's work and allowing me to copy some material from his files, to Alan Freed for his willingness to talk about his website and link it to my research, to Alan Juffs for bringing the WTAE discussion board to my attention, to Dan Baumgardt for help in analyzing the discussion board and for his work on the Wikipedia entry for Pittsburgh English, to Christine M. Neuwirth for her help with sources on new media and interactivity, and to Jennifer Andrus and Scott F. Kiesling for being willing sounding boards and offering new ideas throughout the project. Editor Talbot Taylor and an anonymous reviewer provided a number of very useful suggestions for polishing the final version.
} 
These questions are addressed by asking how a set of linguistic forms that can be heard in southwestern Pennsylvania have come to be thought of as "Pittsburghese," an imagined (in Benedict Anderson's (1991) sense) dialect often thought to be unique to the Pittsburgh area, and tightly linked to local identity (Johnstone, Andrus, and Danielson 2006; Johnstone and Kiesling 2008). Exploring the roles of print newspapers, a website, an online discussion board, and a Wikipedia entry in this process, the paper focuses on how the sources of expertise about what is known as "Pittsburghese" have changed over time, tracing how communications media that are interactive in different ways have been involved in allocating and reallocating rights to describe and evaluate local speech and in making it possible to contest these rights.

This paper contributes in several ways to the large and growing body of work on the discursive construction of language varieties. It takes a step beyond current (and compelling) work on the discursive history of standard varieties and the institutional expertise associated with the formation of standards (often in colonial or post-colonial contexts) to exploring the discursive history of a nonstandard variety, in a situation in which the role of institutionally sanctioned experts has always been contested, and local laypeople have sometimes won such contests. In addition, in exploring the roles of communication technology and technological change, it focuses on a relatively unstudied and increasingly important aspect of the language-making process. On the basis of the analysis, it is argued that scholars interested in the historical process of language-making as well as those interested in interaction with the public on the topic of non-standard varieties can benefit from thinking about the role of technology in determining whose voices are heard when. 
In what follows, I first describe the historical and geographical context of the Pittsburghese phenomenon and summarize the work on language-making, language expertise, and new media studies on which I draw. Next, I trace changes in how expertise about Pittsburgh speech is allocated, claimed, and negotiated in four communications media: print newspapers, a website, an email discussion forum, and a wiki. Finally, I discuss the significance of these findings for the study of languagemakng more generally and their implications for linguists who are interested in making our work speak to our nonspecialist publics.

\section{Pittsburgh speech and Pittsburghese ${ }^{2}$}

Pittsburgh is in southwestern Pennsylvania, separated from the East Coast of the U.S. by the Allegheny Front of the Appalachian Mountains and from nearby cities by political and cultural boundaries. For a variety of topographical, historical, political, cultural, and economic reasons, people in the area have always had a sense of geographical exceptionalism. (See, for example, Zelinsky 1980.) Pittsburghers' identity has always been linked to the city rather than to the state or the region, and the identity of the city was long linked to the dominant industry of the region, steelmaking in all its phases, from coal-mining to the production of coke fuel for the blast furnaces to the final rolling, molding, and pressing operations. Pittsburgh was the "Iron City," the "Smoky City," the "Steel City;" the local football team is the Steelers; local folk heroes were larger-then-life steelworkers like Joe Magarac, who could supposedly use his bare hands to squeeze

\footnotetext{
${ }^{2}$ For a much more detailed account of the social history of Pittsburgh speech and Pittsburghese, see Johnstone, Andrus, and Danielson 2006.
} 
molten steel into rails. Most working-class boys assumed they would follow their fathers into the mines and mills.

Until the middle of the $20^{\text {th }}$ century, the only linguistic variation most Pittsburghers were aware of was variation between English and the many languages spoken by Eastern and Southern European immigrants who came to the area to work in the steel industry. Working-class Pittsburghers whose parents spoke no English, or accented English, learned the English of their peers. In keeping with the "doctrine of first effective settlement" (Labov 2001, 503-504), many aspects of the English of the original English-speaking settlers of the region, most of whom were Scots-Irish, were carried along over many generations. By 1950, Pittsburghers with many different ancestries were monophthonizing /aw/ in words like out, house, and about, fronting /u/ in words like coat and ocean, vocalizing /1/, and using Scots-Irish words like redd up, nebby, and you'uns and Scots-Irish constructions like the ones illustrated in "My mother was 80 whenever she died," or "Anymore electric heating is cheaper than gas."3 Since most working-class Pittsburghers heard only the variants they themselves used, variability was not a resource for sociolinguistic work. An outsider studying the area could have correlated the use of local forms with local birth and residence (Kiesling and Wisnosky 2003). From insiders' perspective, though, like that of one of the people I interviewed, "Everybody talked that way," so "[we] didn't even hear it."

\footnotetext{
${ }^{3}$ On the Scots-Irish origin of redd up, see Dressman 1979. Crozier (1984) points out that this was also a northern English form, as is nebby. The people who were resettled in Ulster during the Ulster Plantation of the $17^{\text {th }}$ century were mainly lowland Scots, but some were from northern England (Dunaway 1944), so arguments about the Scots-Irish origin of words used in North America must be based both on the words' origins in the English of lowland Scotland, northern England, and northern Ireland, and their distribution in North America. On nebby, see the Oxford English Dictionary and the Dictionary of American Regional English. On you'uns, see Crozier 1984, 326-327; Montgomery 2002. On Scots-Irish morphosyntactic features in US English, see Montgomery 1989; 2000. On the punctual use of whenever, see Montgomery and Kirk 2001. On positive anymore, see Crozier 1984, 318; Montgomery 1989, 241-242.
} 
Geographic and social mobility during the latter half of the $20^{\text {th }}$ century made local linguistic features hearable to working-class Pittsburghers, as they began to come into contact with people who spoke differently and, accordingly, began to adjust their speech to sound more correct or cosmopolitan or, alternatively, more like their peers'. During World War II, many men (and some women) travelled in the military. By the 1950s, with labor unions at their strongest, working-class Pittsburghers could afford to move from the densely packed, mono-ethnic neighborhoods near the mills, where they had grown up, to the suburbs, and to take vacations at Atlantic coast beaches. They began to notice linguistic variation correlated with where a person was from and what his or her social status was, and they began to use this variation to do social work.

The local steel industry, in decline since the 1920s, had been propped up during World War II for the production of war materiel. But advances in transportation technology such as the development of powerful diesel locomotives meant that steelmaking no longer required the same set of co-present natural and human resources as before, and steelmakers had begun to look for production sites where labor was cheaper. The industry began to shrink again after the war. The sudden collapse in the 1980s of what was left of the city's steel production put a generation of working-class Pittsburghers out of work, forcing many to move away and all to wonder who they now were, and who cared.

The decline of the steel industry caused people to look for new ways to imagine what it meant to be a Pittsburgher, and a set of local linguistic forms that were now

\footnotetext{
${ }^{4}$ Some regional U.S. dialects had been represented in the media since at least the later $19^{\text {th }}$ century, in "local color" fiction, touring variety shows, and film, and on radio and television. Pittsburgh's was not among these, as it has never been much known outside the Pittsburgh area.
} 
associated with localness and working-class lack of pretension were available for this purpose. Over the past 50 years, Pittsburghese has come to be iconic of local identity, to the point that almost every reference to localness in the media includes (or is) a reference to local speech. A stereotypical working-class Pittsburgher is sometimes referred to as a "Yinzer," a term built on the $2^{\text {nd }}$-person plural pronoun yinz (from you'uns), Pittsburghese shirts, coffee mugs, and shot glasses are for sale almost everywhere local souvenirs are for sale, and characters ranging from graffiti artists to the Mayor to talking dolls use Pittsburghese.

\section{Expertise and Language-making}

Local rules for and ideologies about text-building reflect and shape local rules for and ideologies about expertise and knowledge production. As Geoffrey Raymond (2000; Heritage and Raymond 2005) shows, expertise is not simply brought into interaction as a pre-existing right, but rather negotiated in interaction. The rules of engagement for such negotiation differ from activity to activity and from era to era. For example, Western ideas about expertise, authorship, and intellectual property are partly based on the idea that knowledge can be produced by a single individual, acting alone (Charney 2003). Since the $18^{\text {th }}$ century, scientific expertise has been defined as expertise produced via systematic empirical procedures, and it has increasingly moved out of the purview of educated laypeople and into the narrower purview of accredited experts in universities and industrial research laboratories.

Among these accredited experts are professional linguists. As a true science is thought to need an empirical object of study, linguists have had to find a way to think of 
language in general, and languages in particular, as objects (rather than, say, as processes). As Jesper Hermann puts it $(2008,97)$, “Linguists for a long time rightly regarded themselves as professional guardians of 'language,' and consequently had a vested interest in treating [language] as an independently existing 'thing' they looked after." In doing so, they lost sight of the ways in which, in Paul Hopper's well-known formulation, grammar is emergent rather than a priori (Hopper 1988). That is to say that, for the most part, speakers do not create utterances by deploying the rules of grammar, but rather by repeating, varying, and combining bits of languaging they have experienced before. ${ }^{5}$ But in order to be the sort of "thing" science requires it to be, linguists' object of study has had to be based on abstractions, generalizations based on retrospective analysis of written-down discourse or discourse implicity treated as if it were writtten down (Harris 1980, 6-13). This has led to the idea that discourse is actually produced through the deployment of the sorts of items and rules that are needed to describe linguistic features and languages as objects. As Nigel Love explains it $(2009,26)$ "Abstraction in one particular dimension gives rise to the decontextualised reifications we recognise as linguistic units. First-order language-use may then come to be understood as the deployment by instantiation of these objects."

What linguists and laypeople alike actually experience in daily life are people talking, no two people or situations alike, together with metapragmatic signals (Silverstein 1993) that particular instances of variation need to be attended to, because the presence of one variant versus another makes a semiotic difference. Variation can make various kinds of difference, sometimes indexing differences in denotational

\footnotetext{
${ }^{5}$ Beginning learners of foreign languages may piece together sentences by deploying rules they have learned in advance, but this is the exception, not the norm, and it does not result in fluent face-to-face interaction but rather contributes to a language game of a different sort.
} 
meaning, sometimes differences among speakers' identities, sometimes differences among situations, and so on. ${ }^{6}$ A feature that has been indexically linked with a particular social identity or recurring situation, is, to use Asif Agha's $(2003 ; 2006)$ term, "enregistered." A set of features that have been enregistered with the same identity or situation can come to be thought of as an (objectively delimitable) variety: a register, in the more traditional sense, a style, a dialect, or a language. As Love puts it $(2009,26)$, "codification of a consistent set of [reified form-function links] is essentially what gives us a language."

Much of Roy Harris's work has explored the history of language-making and linguistic expertise in the Western intellectual tradition, tracing the ideas that underlie how mainstream linguists have come to think about their object of study (Harris 1980; 1981; 1987). Linguistic anthropologists have widely adopted the framework of "language ideology” (Schieffelin, Woolard, and Kroskrity 1988; Woolard and Schieffelin 1994) for thinking about cross-cultural ramifications of how people imagine talk, language, and linguistic expertise. Judith Irvine, for example, has written extensively about how Western language ideology shaped the history of African linguistics (Irvine 1995; 2008; 2009; see also Blommaert 2008). In a different post-imperial context (North America), David Samuels explores how Christianity, through the language ideology required for translating the Bible, shaped the Apache sense of what it takes to be a language expert. Dan Knox (2001) explores how "expert" and "enthusiast" institutions have legitimized and politicized the "Doric" language and culture of northeastern Scotland, turning them from everyday practices into "spectacles." Like Knox's, much of this work is focused on

\footnotetext{
${ }^{6}$ For Silverstein, metapragmatic signs point only to "social" differences, not denotational ones. I extend the idea to cover meaning in general, since I see no way of separating "social" from "denotational" meaning.
} 
the role of political institutions in determining "the boundaries of languages and disciplines" (Gal and Irvine 1995). The same is true of much of the literature on the standardization of English (James Milroy and Lesley Milroy 1985; Cameron 1995; Agha 2003; Bhatt 2002), where the institutions involved include governments, the media, and the educational establishment, as well as the discipline of linguistics. (Milroy and Milroy also explore the role of people who make claims to language expertise outside of institutional frameworks, such as writers of letters to newspaper editors complaining about English usage, in shaping the history of Standard English.)

Because linguists and laypeople have different experiences of regional variation, filtered through different ideologies about what "dialects" and "regions" are, the entity that linguists are constructing when they talk about Pittsburgh speech is somewhat different than the one laypeople construct. Table 1 summarizes some of the differences.

\begin{tabular}{|l|l|}
\hline What linguists are describing & What laypeople are describing \\
\hline $\begin{array}{l}\text { "Pittsburgh speech," "the western } \\
\text { Pennsylvania dialect area" }\end{array}$ & "Pittsburghese" \\
\hline $\begin{array}{l}\text { The most significant features are words, for } \\
\text { earlier dialectologists; phonological } \\
\text { features, for contemporary sociolinguists. }\end{array}$ & The most significant features are words. \\
\hline $\begin{array}{l}\text { Pittsburgh speech is the intersection of a set } \\
\text { of features, most of which are shared with } \\
\text { other areas. }\end{array}$ & $\begin{array}{l}\text { Pittsburghese is a set of features all of } \\
\text { which are all used only in the Pittsburgh } \\
\text { area. }\end{array}$ \\
\hline $\begin{array}{l}\text { Some Pittsburghers use features of } \\
\text { Pittsburgh speech, others do not. }\end{array}$ & $\begin{array}{l}\text { All Pittsburghers use at least some features } \\
\text { of Pittsburghese. }\end{array}$ \\
\hline $\begin{array}{l}\text { The use of local features is linked with } \\
\text { gender, class, race. }\end{array}$ & $\begin{array}{l}\text { Some younger Pittsburghers do not see } \\
\text { Pittsburghese as linked to class, though } \\
\text { older Pittsburghers do. }\end{array}$ \\
\hline
\end{tabular}

Table 1: Linguists' vs. laypeople's descriptions of local speech in Pittsburgh 
An account of Pittsburgh speech from a linguist's perspective would avoid the term "Pittsburghese," both for ethical reasons (it can have negative connotations) and because as noted above, dialects are metalinguistic constructs, not empirical objects waiting to be described. There is no set of (even roughly) contiguous lexical, phonological, or morphosyntactic isoglosses encircling Pittsburgh. What can be seen from maps of the spatial distribution of linguistic features is that there is an area in western Pennsylvania which may be undergoing a distinctive phonological chain shift (Labov, Ash, and Boberg $2005,271-272)$, and that a number of nonstandard phonological, lexical, and morphosyntactic features used in the Pittsburgh area are regionally variable in the U.S., though none are unique to Pittsburgh or even western Pennsylvania . A linguist who wanted to use the word "dialect," with all its ideological presuppositions, might use a term such as "the western Pennsylvania dialect area." But if linguists were to study speech in Pittsburgh without assuming that their object of study was a dialect (as have my colleagues and I), they might instead call it "Pittsburgh speech," a term which does not suggest that the ways people use language in Pittsburgh constitute a neatly bounded entity. Laypeople, on the other hand, use the term "Pittsburghese." This reflects the widespread assumption that Pittsburgh speech does constitute a dialect with clear boundaries, a set of forms used in Pittsburgh and nowhere else.

Although dialectologists in the dialect atlas tradition based their maps on the distribution of lexical items across space, they also made detailed phonetic transcripts. Contemporary sociolinguistics favors phonological and grammatical features over lexical ones. When laypeople talk about Pittsburghese, on the other hand, they are almost always talking about words. Pittsburghese is "the words we use that nobody else uses," 
as one interviewee said; others provided similar definitions. When phonological features are noticed, they are edified, represented invariably in the same small set of words. For example, the monophthongal /aw/ that (a linguist would say) occurs in all phonetic environments except in words consisting of single open syllables is represented in lay descriptions as "dahntahn" (downtown) or "aht" (out). Some interviewees thought, in fact, that it was the word downtown, rather than its pronunciation, that was distinctive, though they were not sure why. Citation forms for grammatical features are also usually drawn from very small sets of set phrases such as "the car needs washed" (a feature a linguist would identify as a nonstandard complementation rule with need, want, and like).

Linguists expect the use of Pittsburgh speech features to vary according to stylistic and demographic factors, and they see this as an important fact about this, or any, variety. In Pittsburgh, they note that the use of local features is linked to gender, class and race. Older Pittsburghers talk about the class-linked aspect of "Pittsburghese", although often in terms of education rather than social class itself. Younger Pittsburghers notice this sort of variation less, in some cases because they experience Pittsburghese mostly in the form of written representations of it. Additionally, linguists are careful to point out that they are focusing on how white Pittsburghers talk. Lay African American Pittsburghers see Pittsburghese as a white phenomenon (Eberhardt 2009), while white laypeople tend to talk as if everyone in Pittsburgh spoke Pittsburghese.

Expertise about Pittsburgh speech has always been up for grabs. As any sociolinguist or dialectologist knows, claims to knowledge about dialects on the basis of professional expertise in linguistics do not always trump claims based on being there or being a native. As I will show below, print newspaper articles about Pittsburgh speech 
have more often than not juxtaposed claims by professional linguists with headlines and images representing the lay conception of it. Sometimes the possibility that academic linguists are not the best source of language expertise becomes overt. In a 2008 article in the Pittsburgh Post-Gazette, for example, a newcomer to the city claimed to have chosen a popular website (discussed in detail later on in this paper) over a scholarly one as a source for information about local speech (Petrucelli 2008). After claiming that he "still cannot understand most of the people some of the time" after a year in Pittsburgh, Alan Petrucelli asserts that "Pittsburghese is a language all its own," echoing a claim that has been made in the press without apparent need for substantiation since at least 1973 (McGough 1973, "Pittsburghers Have a Dialect All Their Own"). He then describes how he went about finding out more:

To dig deeper, I decided to find a dialectologist and found one in Barbara Johnstone, professor of linguistics and rhetoric at Carnegie Mellon University. She and her sociolinguist associate, Scott F. Kiesling, associate professor of linguistics at the University of Pittsburgh, have put together a Web site (english.cmu.edu/pittsburghspeech) that offers a compressive [sic] look at what and why and how and when and who of Pittsburghese. Although it's user-friendly, the site is too academic for me, with occasional "big" words such as "monophthongization" rearing their six-syllable heads. Important stuff? Yes. But I jest wanna have fun. 
And then I went to www.pittsburghese.com, a marvel of a site that promises I can learn Pittsburghese in a day!

Although Petrucelli finds the linguists" website "comprehensive" (or "impressive") and "important," he does not quote or paraphrase any information from it. Instead, he claims that it is "too academic" and not enough "fun," in contrast to the pittsburghese.com site. The respellings in Petrucelli's article make it clear that he has borrowed heavily from the latter site, where Pittsburgh speech is (from a linguist's point of view) conflated with non-standard speech in general, fast speech ("wanna”), and eye dialect (“jest”).

\section{(New) Media and Interactivity}

In research about computer-mediated communication and new media studies, the term "interactive" is often used to describe systems of communication in which the receiver of a message is not just a passive consumer. Exactly what this can entail has proven to be very difficult to pin down. As it is often used, the term "interactive" is shot through with ideological connotations: whatever it actually is, interactivity is a good thing. As Jensen $(1999,161)$ puts it, “... it seems relatively unclear just what 'interactivity' and 'interactive media' mean. The positiveness surrounding the concepts and the frequency of their use seem, in a way, to be reversely [sic] proportional to their precision and actual content of meaning." A number of scholars have offered typologies of the kinds of interactivity made possible by various communications media and realized in the ways they are used (Jensen 1999; Downes and McMillan 2000; McMillan 2002; Herring 2007; for an overview, see Lister et al. 2009, 21-25). Interactivity can refer to the possibility for users 
to make changes to the software they use, to edit the texts they read, to converse with other users, or some combination of these, and there can be varying degrees of reciprocity in user-to-user interactivity. Interaction can be synchronous (occurring in real time) or asynchronous, one-way or two-way, anonymous or not; some media allow for the transcript of the interaction to be archived and some do not. And so on.

In what follows, I discuss four communications media that are interactive in different ways. Figure 2 summarizes the features they share and those on which they differ.

\begin{tabular}{|c|c|c|c|c|}
\hline & $\begin{array}{l}\text { newspaper } \\
\text { articles }\end{array}$ & Pittsburghese.com & $\begin{array}{l}\text { WTAE } \\
\text { forum }\end{array}$ & $\begin{array}{l}\text { Wikipedia } \\
\text { entry }\end{array}$ \\
\hline $\begin{array}{l}\text { Is two-way } \\
\text { communication } \\
\text { possible, i.e. } \\
\text { sender-to- } \\
\text { receiver and } \\
\text { receiver-to- } \\
\text { sender? }\end{array}$ & Yes & Yes & Yes & Yes \\
\hline $\begin{array}{l}\text { Is the } \\
\text { communication } \\
\text { synchronous (i.e. } \\
\text { in real time)? }\end{array}$ & No & No & No & No \\
\hline $\begin{array}{l}\text { Can users be } \\
\text { anonymous or } \\
\text { use a } \\
\text { pseudonym? }\end{array}$ & Yes & Yes & Yes & Yes \\
\hline $\begin{array}{l}\text { Is the medium } \\
\text { registrationally } \\
\text { interactive (i.e. } \\
\text { receivers can } \\
\text { register their } \\
\text { own messages)? }\end{array}$ & $\begin{array}{l}\text { Yes (although } \\
\text { the receiver's } \\
\text { message is } \\
\text { discontinuous } \\
\text { in space and } \\
\text { time) }\end{array}$ & Yes & Yes & Yes \\
\hline $\begin{array}{l}\text { Is the format of } \\
\text { users' } \\
\text { contributions } \\
\text { formatted by the } \\
\text { sender? }\end{array}$ & $\begin{array}{l}\text { No: } \\
\text { Responses } \\
\text { have a generic } \\
\text { "letter to the } \\
\text { editor" format. }\end{array}$ & Yes & $\begin{array}{l}\text { No: } \\
\text { Responses } \\
\text { have an } \\
\text { emergent } \\
\text { format shaped } \\
\text { by the need to } \\
\text { construct }\end{array}$ & Yes \\
\hline
\end{tabular}




\begin{tabular}{|c|c|c|c|c|}
\hline & & & authority. & \\
\hline $\begin{array}{l}\text { Is user-to-user } \\
\text { interaction } \\
\text { mediated by } \\
\text { responses to the } \\
\text { original text as } \\
\text { well as the } \\
\text { original text? }\end{array}$ & $\begin{array}{l}\text { Possibly } \\
\text { (Another letter } \\
\text { writer might } \\
\text { have seen a } \\
\text { previous } \\
\text { letter, or not.) }\end{array}$ & Yes & Yes & Yes \\
\hline $\begin{array}{l}\text { Can users add to } \\
\text { the existing } \\
\text { text? }\end{array}$ & No & Yes & Yes & Yes \\
\hline $\begin{array}{l}\text { Can users } \\
\text { change the } \\
\text { existing text? }\end{array}$ & No & No & No & Yes \\
\hline $\begin{array}{l}\text { Can users } \\
\text { communicate } \\
\text { with other users } \\
\text { via the text (i.e. } \\
\text { by what they do } \\
\text { to the text)? }\end{array}$ & No & Yes & Yes & Yes \\
\hline $\begin{array}{l}\text { Can users talk } \\
\text { with other users } \\
\text { on a separate } \\
\text { channel? }\end{array}$ & No & No & No & Yes \\
\hline $\begin{array}{l}\text { Can a user's } \\
\text { authority be } \\
\text { contested? }\end{array}$ & $\begin{array}{l}\text { Yes (but this } \\
\text { is rare) }\end{array}$ & No & Yes & Yes \\
\hline $\begin{array}{l}\text { Who get to be } \\
\text { the experts? }\end{array}$ & $\begin{array}{l}\text { Reporters and } \\
\text { their sources: } \\
\text { Pittsburgh } \\
\text { laypeople and } \\
\text { later linguists. }\end{array}$ & $\begin{array}{l}\text { Laypeople, } \\
\text { Pittsburghers or not; } \\
\text { users can make } \\
\text { some reference to } \\
\text { their location. }\end{array}$ & $\begin{array}{l}\text { Laypeople, } \\
\text { Pittsburghers } \\
\text { or not, } \\
\text { although } \\
\text { personal } \\
\text { experience is } \\
\text { valuable. }\end{array}$ & $\begin{array}{l}\text { Linguists, } \\
\text { other people } \\
\text { with } \\
\text { "scientific" } \\
\text { knowledge. } \\
\text { Personal } \\
\text { experience } \\
\text { is irrelevant. }\end{array}$ \\
\hline
\end{tabular}

Table 2: Features of interactivity in four media in which people talk about Pittsburgh speech.

It should be noted that technology does not arise in a cultural vacuum or dictate what people do with it. The constraints and affordances listed in Figure 1 are both 
technological and ideological. Technology is shaped by (its ideologically shaped) use, and the use of technology use is shaped by (the ideologically shaped) technology.

All four of the communications media I will discuss allow for two-way communication between the original message sender and receivers of the message, all are asynchronous, and all allow message-responders to be anonymous or pseudonymous. All four are "registrationally interactive," which is to say that receivers of the original message can send messages back, although print newspapers make it unlikely that the original article and the letter-to-the-editor response will actually be experienced at the same time or in the same place. Beyond that, the media differ in ways I will describe below. Some force users to respond using a tightly-controlled format, others do not. In some, users can add to and/or change the original text; in the wiki, users can also talk to one another on a separate page. In consequence, as I will show, the four media allow for expertise of different sorts to be represented, and some media allow expertise to be contested while others do not. This results, ultimately, in different voices being heard as those of language experts.

My analytical methods in what follows center on discourse analysis of the structural and functional elements of texts, contextualized by more than nine years of sociolinguistic interviewing, participant observation, and other kinds of ethnographic and experimental data collection in the Pittsburgh area.

\section{Newspaper Articles, 1952-1992}

A corpus of newspaper articles about Pittsburgh speech dating from the 1950s through the early 1990s shows how popular, person-on-the-street language expertise, 
epistemically based on personal experience and personal observation, came to be supplemented and in some cases replaced by technical expertise based on specialized knowledge and knowledge-producing procedures like scholarly research. Print newspaper reports from this period are minimally interactive, as judged by the fact that they full fewer of the criteria listed on Figure 1 than any of the other three, and, as preserved in the historical record, they are even less so. Although readers could write letters to the editor meant to register their support for or a correction to the knowledge claims made in an article, the letters were not published with the articles, and there was never any guarantee that a correction would be made. Letters to the editor were not archived together with the articles they responded to, so, as these articles are experienced now, they represent only the voice of the reporter and the people the reporter chooses to quote or paraphrase. There are 21 articles in this corpus, which was assembled by a librarian at the Carnegie Library of Pittsburgh ${ }^{7}$ and from the files of Patricia Parslow, widow of dialectologist Robert Parslow (see below). All are from local publications and are about Pittsburgh speech. There are four articles from the 1950s, three from the 1960s, seven from the 1970s, four from the 1980s, and three from the 1990-1992 period. In articles dating from 1952 to 1965 , observations about local speech and explanations for its peculiarities are presented in the voice of the article's author and members of the general public, often outsiders who have moved to the city. In either

\footnotetext{
${ }^{7}$ According to librarians at the Carnegie Library, Rose Demorest, the first head librarian of the Pennsylvania department, probably started the collection. The first newsprint clipping (as opposed to microfilm copy) is from 1952, making this the likely date that the file was created. The file consists primarily of newspaper and magazine articles, but it also includes several "Pittsburghese" glossaries, as well as excerpts from Kurath and McDavid's (1961) The Pronunciation of English in the Atlantic States. While a majority of the articles focus on pronunciation, vocabulary, and grammar, there are several articles on other language topics, such as issues surrounding Pennsylvanians whose first language is Spanish, local proverbs, and American African Vernacular English "slang." Andrew E. Danielson, a former student of mine, came across the archive and did the initial analysis of it (Danielson 2001; Johnstone and Danielson 2001), which I draw on here.
} 
case, claims about local speech are based on personal experience rather than technical expertise. The first article in the corpus (Gilbert Love 1952) is a collection of observations paraphrased from letters to the editor, including "a woman from Philadelphia who moved here several years ago" and "a man from Minneapolis". Writer Gilbert Love's voice is heard mainly as the compiler, although his own observations are once presented: "Many of us deny that we use those phrases..." Another writer describes the observations of "a friend, newly come to Pittsburgh," who, "like all newcomers...duly noted the rising inflection which native Pittsburghers employ" (Berhhard 1959). In two articles by George Swetnam (Swetnam 1959a; 1959b), the sole voice is that of the writer, who bases his claims about local speech on his own experience, including noticing a "well-educated friend" use anymore in a distinctive way. The first article that cites an academic expert is from 1967 (Gleason 1967). The expert is Robert Parslow, then a recently-arrived instructor of linguistics at the University of Pittsburgh, whose specialty was dialectology (Christina Paulston, personal communication, Feb. 19, 2008). Parslow was working on a doctoral dissertation under Raven McDavid, Editor of the Linguistic Atlas of the Upper Midwest. The article appears to be the outcome of an interview by writer David Gleason with Parslow. Parslow is introduced as "instructor in linguistics at the University of Pittsburgh" and the article consists entirely of quotes from Parslow (in quotation marks) and paraphrases of his words. No other voices are heard. The quotatives used of Parslow represent him as authoritative: he "hastens to point out (that the Pittsburgh area doesn't have a monopoly on different ways of writing or saying things)," "knows (that people say things differently, depending on [where they are from])," explains," "points out," "emphasizes," 
and "reports." Author Gleason cites the Linguistic Atlas of the United States projects as the source for one claim about US dialectology ("The United States is divided into regions, according to speech habits, in the Linguistic Atlas") but Parslow is represented as citing no source for any of his claims about Pittsburgh speech or dialect geography in general, representing them, rather, as common expert knowledge, as in this passage:

"Gum band - for rubber band - is exclusively Pittsburgh, but you will find 'rubber binders' substituted for it in some parts of the country," explains Mr. Parslow. 'It's easily explained - the use of the word 'gum,' that is. Rubber is a gummy material. In some places, galoshes, for instance, are called 'gum boots' for the same reason."

Parslow's certainty is underscored by his use of the simple present ("gum band ... is exclusively Pittsburgh"; "galoshes ... are called 'gum boots"”) and his teacherly stance is further performed in expressions like "you will find" and "it's easily explained."

Parslow's voice dominates in two subsequent articles (McGough 1973; Huzinec 1978), which are about his planned research in Pittsburgh. ${ }^{8}$ Other articles after 1967 almost invariably cite -- usually by name -- one or more sources identified as having technical expertise: "some expert linguists" (Swetnam 1972), "Anita Panek, secondary English teacher" (Browne 1976), "speech teachers" (Bloom 1977), H. L. Mencken (Bloom 1977), Frederick Cassidy and Joan Hall of the Dictionary of American Regional English (McHugh 1979), and other "educators," "scholars," and "local linguists." When articles begin, starting in the 1980s, to turn from treating local speech as an curious

\footnotetext{
${ }^{8}$ Parslow passed away before publishing any scholarly work about Pittsburgh speech.
} 
oddity to talking about its situational appropriateness or inappropriateness, experts come to include job counselors and corporate human relations managers (Warnick 1990; Braknis 1991; Kloman 1992).

However, people on the street continue to be quoted from time to time. Sometimes their views are contrasted with "professional opinion," but in two articles from the early 1990s, ordinary citizens are represented as having the same degree of expertise as technical specialists, just arising from a different source, personal experience. In an article about local speech in the Lawrenceville neighborhood (Warnick 1990), all but three of the reporter's sources are identified by means of a similar appositive phrase: Samuel Lewis ("manager of Kay Drug Co. on Butler Street"), Sam McCool ("author of 'Sam McCool's New Pittsburghese'"), Richard Enos ("a Carnegie Mellon University English professor who teaches rhetoric"), Christina Bratt Paulston ("a University of Pittsburgh Linguistics Professor"), Maryanna Baldauf ("a lifelong neighborhood resident"), Bernice Palmiere ("principal of St. John Neumann regional Catholic Elementary School”), JoAnne Eresh (“director of the Pittsburgh School district's division of writing and speaking”), Linda Blackman (“president of The Executive Image, Inc.”) The other three sources are people on the street in Lawrenceville, identified by name and age: “George Mihelcic, 19”, “Tim Frolini, 17,” and "Karl Rogosz, 32”). The only quotative author Warnick uses is "says," and as it is used of all his sources it does not rank them with regard to expertise.

Starting in the 1960s, the newspaper articles in the corpus begin to set textual exposition of "the facts" about Pittsburgh speech (whether the source for these facts be popular or technical) against a visual background of popular representations of the dialect 
and its speakers. At first these are cartoon illustrations: a man using a picture to explain to a shopkeeper what a "gumband" is (Gleason 1965), a man in Pittsburgh Pirates baseball cap pointing two other people in the direction of a sign saying "Dahn tahn [downtown] Pittsburgh" (Gray 1968), the outline of Pennsylvania with seven openmouthed cartoon characters in its southwestern corner and the words "dahntahn" [downtown], "wants washed," and "ahtside" [outside] (Gleason 1967), a sports fan surrounded by representations of regional words including "youn's" [you, pl.], "red up" [tidy up], and "crick" [creek] (Swetnam 1972). Later there are headlines that include representations of Pittsburgh speech. The first of these appears in 1978 ("Pitt prof finds Pittsburghese a slippy subject" (Huzinec 1978). Others include "This column needs read" (Leo 1982), "We'uns sure stretch the king's English" (Davidson 1984), “Lawrenceville aside, fewer of yunz speak Pittsburghese” (Warnick 1990), "Internet n’at" (Gitman 1997), and "Pals send tape an 'at to priest in Rome" (Ove 1998).

The role of the popular voice in these representations is ambiguous. When it appears in a headline, the popular voice represented by the respelled words has the effect of framing the more expert voice. The expert cited in the article is talking about something that has already been introduced in the headline in a way that presupposes the local knowledge required to recognize and understand the Pittsburghese forms. The expert's role is framed as that of filling in the background blanks about something that is already known: that slippy or needs $x$-ed or we'uns are local forms, for example. Since headlines are written after articles are submitted, often by a different writer, it is impossible for the technical expert to contest the popular knowledge they represent (such as the claim that we'uns is a Pittsburgh form, when, as far as I know, no Pittsburgher or 
dialectologist has ever claimed that it is). When it is in a cartoon, what the popular voice says about local speech is presented as an illustration of what the voices in the article say, even though the two representations of local speech may be in conflict, the illustration representing forms the expert would not consider local, such as eye dialect, terms the expert would not consider technical, such as Pittsburghese, or activities the expert would not sanction, such as using jokey respelling as a way of representing nonstandard speech.

To summarize, the trend over time in the newspaper articles is clearly towards the privileging of arguments about local speech based on technical expertise over person-inthe-street personal-experience arguments. This is particularly true of the body of the articles, where the reporter is in control of the representation of expertise and where, starting with the first article about Robert Parslow, the voice of technical experts is more often meant to be taken as authoritative than is that of the layperson, who sometimes has no voice at all. But headlines and illustrations, created by other people, often push against that locus of authority, representing the experts as simply elaborating on things Pittsburghers already knew.

\section{Pittsburghese.com Website, 1997- 2003}

In the 1990s, the development of more interactive media enabled the center of epistemic balance to shift. A website called "Pittsburghese" (http://pittsburghese.com) encouraged visitors to contribute entries to a list of "Pittsburghese" words and phrases.

Pittsburghese.com is the work of a local web designer, Alan Freed, who mounted it in 1997 as a way of calling attention to his web-design business (Voice of America 2000, Alan Freed, personal communication, June 27, 2002). The site carries banner ads for 
small, Pittsburgh-based enterprises such as souvenir wholesalers and photo suppliers. Promising that readers can "learn Pittsburghese in a day," the site includes some "Pittsburghese calisthenics," a "translator," and "audio quiz," as well as a link to a recording of a Voice of America radio program that featured the site (Voice of America). Starting in 2002, at my instigation, a tab called "For Actual Research" linked to a page about my research on the dialect and, from there, to the Pittsburgh Speech and Society website, http://english.cmu.edu/pittsburghspeech/, mounted in connection with the research.

The most popular section during the period in question was the "Glossary." Here, visitors could fill in a form on which they listed their name and location and a word or phrase (often spelled in a way that was meant to indicate its nonstandard pronunciation) with a definition and an example sentence. Entries appeared on the site in an invariable format exemplified by this one:

Bawdle Bottle. Gimme a bawdle of arn!

(Submitted by Hank Smoot, Springfield)

Contributions automatically appeared on the site unless Freed deemed them obscene. In 2002, the site was getting 1,000 visits a day, and the glossary had grown to thousands of items (Fleming 2008) ${ }^{9}$

\footnotetext{
${ }^{9}$ Although it is not my focus here to evaluate the actual claims people make about local speech in any of the media I am discussing, this chart gives a sense of what sorts of things glossary entries did.
} 
Although the tone of the entries, and that of the site as a whole, was meant to be humorous, it was by no means clear to all its readers and contributors that the activity was intended as a joke. The reporter for the Voice of America who described the site represented it as "entertaining," and her report was set to the background of "The Pennsylvania Polka" and a song about the Pittsburgh Steelers (the local professional American football team). However, she also represented her discovery of the site as the discovery that the dialect of her youth was real, not just a nostalgic figment of the collective imagination (Voice of America). Although the site's designer and webmaster,

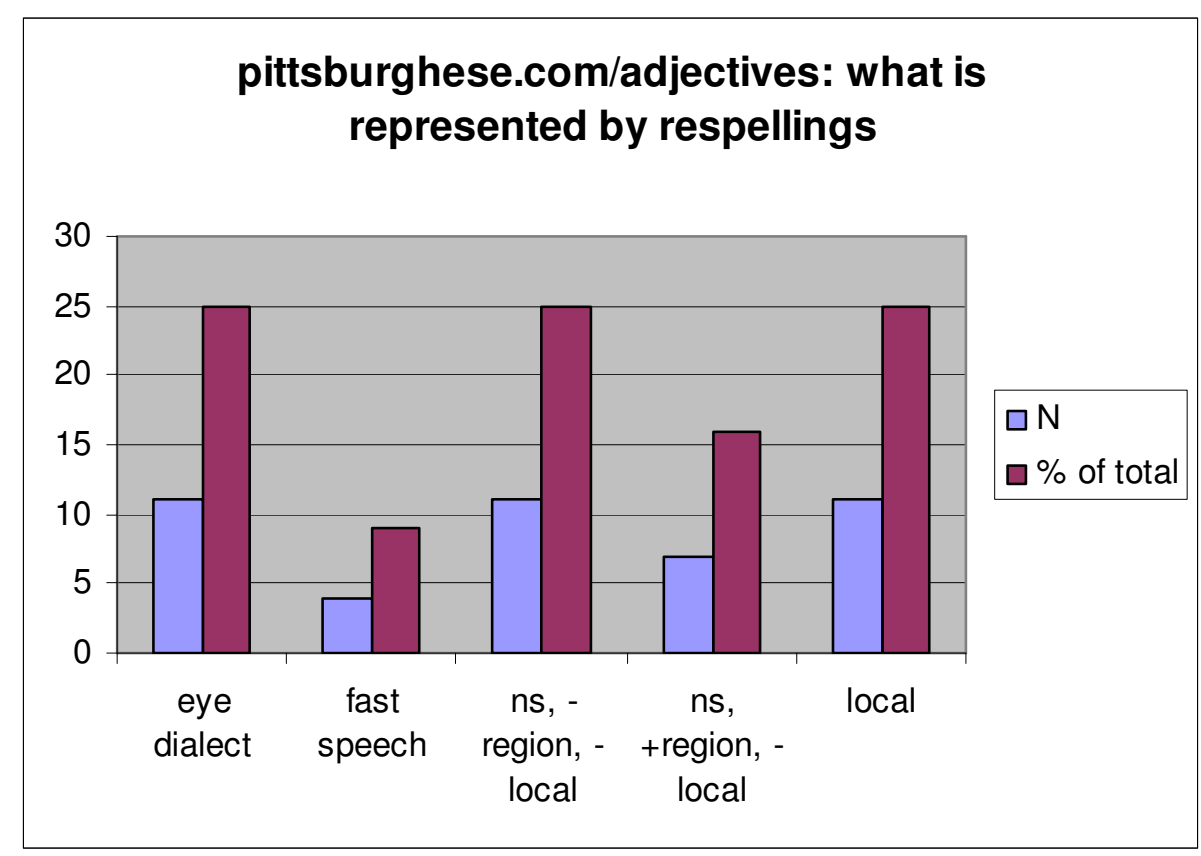

As the chart shows, $25 \%$ of the entries in the "adjectives" section of the glossary represented "eye dialect," nonstandard spellings of standard pronunciations such as "cawfing" for "coughing." Nine per cent represented casual standard pronunciation as shaped by "fast speech "rules: an example is "ig'nernt" for "ignorant." Another quarter of the entries appeared to represent nonstandard usage, but of either a very widespread or a very idiosyncratic nature, as in entries for words like "inneresting" (a widespread nonstandard pronunciation of "interesting"). or "jiagunda" (possibly a family's or even an individual's term for "huge"). An additional 25\% were words that do vary regionally in U.S. English but are not associated with Pittsburgh speech in any other source: "cattywumpus" for "diagonally across from" or "ascared" for "scared." A quarter of the entries represent words or pronunciations that are widely understood, by linguists and/or Pittsburghers, to be limited in geographical range and widely heard in the Pittsburgh area: "lahsy" represents the local monophthongal /aw/ in "lousy," "slippy" is a word of ScotsIrish origin meaning "slippery." 
Alan Freed, later claimed that "there's not a serious word on the whole site" (Freed, email to Barbara Johnstone, 30 Jan., 2008), he also admitted that "every so often people were taking us seriously." Beginning in 2001 or so, this became clear to me, too, when Freed became aware of my work with the dialect and started referring queries he got from students to me. (When I told him about the new Pittsburgh Speech and Society website in June of 2002 he immediately created the link to it, and to me, that I mentioned above.) In other words, the nature of the expertise the site represented was ambiguous: was the person-on-the-street (or person-on-the-World Wide Web) expertise that appeared on the site the kind of expertise you could draw on for, say, a school or university term paper, or not? Freed insisted that the representation of local speech on his website did not represent technical expertise, but some of the site's users either thought it did or did not ask themselves the question.

Around 2003, webmaster Freed turned off the interactive feature that allowed people to contribute new words. According to a newspaper interview, he felt that he had lost control of the site's content: "It got to the point where people were submitting anything Myron Cope [a local sports announcer with a distinctive speaking style] had ever said in his life," Freed was quoted as saying (Fleming 2008). The site is still, as of this writing, accessible, but visitors can no longer experience it as interactive in the same way.

Because anyone could post to it and editorial censoring was minimal, the site diffused expertise about local speech far beyond the few carefully selected local peopleon-the-street whose voices appeared in some of the newspaper articles. Anyone with internet access could, in this medium, claim expertise about local speech simply by 
posting an entry to the list. Participants were unable to argue for their expertise or explicitly indicate its source. Because the form that created the database entries behind the site constrained what kinds of information posters could provide -- name, place, word, definition, and example -- the only way posters could make any sort of claim about the source of their expertise about Pittsburgh speech was by listing Pittsburgh or some nearby place as their location. People not in the Pittsburgh area had no other way to support the implicit claim to expertise they made by posting on the site. Nor did this medium afford users any way to contest the expertise that others implicitly claimed.

\section{An Email Discussion Forum, 2002-2003}

An email discussion board from 2002-2003 afforded an equally large arena for expertise. Unlike the website, however, this forum encouraged participants to make explicit reference to the sources of their expertise, and expertise was sometimes the focus of discussion.

The forum was one a number of discussion threads about topics or events on which a Pittsburgh TV station, WTAE, recently reported. It could be accessed from the station's homepage. This thread was initiated on March 22, 2002, probably in connection with reporting about an academic workshop on Pittsburgh speech that started that day ${ }^{10}$ The version of the discussion prompt to which most contributions appeared to respond was “Is Our Local Dialect Charming Or Embarrassing?," which appeared on its first page. Our analysis of the discussion board (Johnstone and Baumgardt 2004) considered

\footnotetext{
${ }^{10}$ The workshop, held at Carnegie Mellon University, was funded by Carnegie Mellon and the University of Pittsburgh and hosted by Scott Kiesling of the University of Pittsburgh Department of Linguistics and me. It included linguists specializing in regional speech and geographers, historians, and sociologists specializing in the Pittsburgh area.
} 
the roughly $9 \frac{1}{1} 2$ month period from its inception until Jan. 10, 2003. The segment contains 19,253 words; it includes 101 participants, who provide a total of 180 responses. Particularly at the beginning of the discussion, where responses tended to be directly linked to the discussion question (often via lexical cohesion), contributions tended to be quite similar to one another. Note, for example, how this contribution is tied to the discussion question via the use of "charming":

I never realized I spoke Pittsburgheze until my children became older and asked me why I talk funny. Apparently, our teachers spoke the same way and we were never taught the short vowel sounds. I am too old to correct my speaking now. Many years ago, I lived in Rochester, NY and the people knew I was from Pittsburgh, and not only that, they knew I was from McKees Rocks. McKees Rocks has their very own thick Pittsburgh accent. Our dialect is charming and I am proud to speak it!!!!

As did stilesmom, participants often used personal-experience narratives to establish their right to speak by virtue of their "local knowledge" and as inductive support of evaluations of local speech. In addition, participants often engaged in "feature dropping," using or listing words or phrases thought of as local as a way of indexing expertise relevant to evaluating the dialect, as exemplified in this contribution:

...[I've] been out of [there] for 17 years... and still say "melk" instead of milk, gum bands instead of rubber bands, redd up and jaetyet (did you eat yet.) 
Tying one's identity to Pittsburgh and using or mentioning a feature of Pittsburghese were apparently seen as ways to establish oneself as an authority who could credibly make evaluative arguments about the dialect.

A few participants noted academic or quasi-academic sources for their use or knowledge of Pittsburghese. One participant, for example, mentioned the author of a Pittsburghese dictionary (McCool 1982), another referred to an ongoing academic study, and a third mentioned training in linguistics as a source of knowledge about dialect. However, displays of local experience and local knowledge were by far the most common ways of claiming authority to speak in the conversation. Because the format of postings did not allow participants to identify themselves except with a name and a place, expertise had to be claimed in the contribution itself. But unlike on the pittsburghese.com site, both the technology behind the discussion forum and people's sense of how to use it made this possible and almost inevitable. In some cases, these interactional demands lead to an activity we call "vernacular lexicography," or explicit talk about what should be included in the dialect and why. This activity is exemplified in the following excerpts:

I feel that the non-word "ain't" needs to be included.

My wife informs me that my use of "whenever" as opposed to just "when," is Pittsburghese.

"Pop" [carbonated soft drinks] is not limited to Pittsburgh. 
In contributions such as these, the participants explicitly note the normative process they are involved in.

\section{A Wikipedia Entry, 2006}

The democratic diffusion of the right to create knowledge that we see in the progression from newspaper articles to website to discussion forum is often celebrated. However, as Ronkin and Karn (1999), Hill (1995), and others have shown, popular discourse about vernacular speech often enacts racism, classism, and other forms of discrimination, and this is as true for Pittsburgh speech as it is for any other non-standard way of speaking. Many Pittsburghers are deeply offended by representations of the dialect that suggest that they all speak alike, in a stupid-sounding way, and my initial foray into the study of the dialect was the result of a wish to correct some of this widely available misinformation. Thus I turn, finally, to an effort by academics to reclaim expertise about Pittsburgh speech.

In 2006, Dan Baumgardt and I developed and posted a Wikipedia entry on Pittsburgh English (Baumgardt and Johnstone 2006). We chose this medium (in addition to a mounting a website) because we knew the people we wanted to reach - students and other young adults - would be likely to use it before turning to more traditional sources of information. We expected it to be extremely difficult to claim and maintain expertise in a forum that is interactive in new ways and in which expertise is potentially distributed even more widely than in the media discussed above. It turned out to be relatively easy, for reasons I will touch on below.

A wiki (derived from the Hawaiian word for 'fast') is software that allows people to create and edit web pages quickly and easily; it is typically used for collaborative 
projects (Pentzold 2007, 2). Wikis consist of a main page, a page on which drafts and edits can be made and transferred to the main page, and often a revision history function that allows users to see every version of the document and compare different versions. Wikipedia entries also have a Discussion page where users can comment on the topic or on each other's editing or editorial standards.

Anyone with internet access can edit a Wikipedia entry and/or contribute to the discussion. This initially created the expectation that expertise, if not irrelevant altogether, would have different sources in this medium than in a print encyclopedia, where topic authors are selected based largely on academic expertise (Bryant, Forte, and Bruckman 2005). It has turned out, however, that the volunteer editors who patrol Wikipedia in fact rely on the citation of scholarly sources as a major criterion for evaluating entries. With three months of time and effort, Baumgardt and I were able to replace the existing article on Pittsburgh English with an entirely different one in which every claim is attributed to a reputable, printed scholarly source, and every study of the Pittsburgh speech that we knew of is cited.

That article has since been edited, but the editing has only made it more technical and limited participation rights in the editing process to people familiar with the relevant scholarly literature. For example, the list of Pittsburgh words on the site has been edited repeatedly to remove entries that were sourced solely to personal experience. In early 2006 (before our revision was posted), there was a discussion of this issue on the Discussion page of the Pittsburgh English entry during which one of the entry's regular editors made it clear that local knowledge was not a valid source of expertise ("Personal experience isn't good enough"). Weatherman1126 asks, 
What references are needed for the direct terms? Most of it is probally from "experience"/tradition by living in Pittsburgh. --Weatherman1126 15:23, 28 January 2006 (UTC)

Editor angr replies, the same day,

All information on Wikipedia needs to be verifiable and backed up with published sources. Personal experience isn't good enough. Some dictionaries, such as the American Heritage Dictionary, indicate that word is used only in a specific region, so if you can find a citation from one of those that the word in question is unique to Pittsburgh, then that's citing a source. Published dialect surveys and atlases will also often show what words are used where, so that's another place to look for verification. --Angr 16:14, 28 January 2006 (UTC)

Later, another regular editor threatened to delete all un-cited entries in the glossary:

The vast majority of these terms are not cited. These citations need to be added within the next week or I will be deleting them [the terms]. There is a references section, but that's not the same thing as citing; individual terms need to be sourcable. --Chris Griswold 17:06, 11 July 2006 (UTC)

In sum, despite being in material ways the medium with the most potential for interaction between people with different sources of linguistic expertise, Wikipedia as it is actually used is the most insistent that the sole source of legitimate expertise is not only technical but in print. Ironically, the voice of ordinary Pittsburghers - unless they are linguists or 
can cite the literature of sociolinguistics and dialectology - is even less present than it was in the least interactive of media, the pre-internet print newspaper report.

\section{Discussion}

To return to the questions I started with, language expertise is distributed, contested, and negotiated differently in different communications media, depending on the material constraints and affordances of the medium and users' ideologically-shaped expectations about how, and by whom, it is used. In print newspapers, where reporters have the right to decide what sources of expertise to represent, claims about Pittsburgh speech are attributed first to newcomers, whose authority arises from personal experience, then increasingly to people with various kinds of institutionally sanctioned technical authority, including linguists, although people on the street are also sometimes quoted. On the 1990s website, anyone, Pittsburgher or not, could act as an expert. The medium afforded no way to indicate the source of one's expertise and no way to contest the expertise of others or the particular claims about Pittsburgh speech that they made. By contrast, in the online discussion forum from the early 2000s, people could indicate where their expertise came from, and, interestingly, most people did: they used narrative to show that they had local experience, "feature dropping" to show that they had local knowledge, and, occasionally, references to institutional sources of authority like books and scholarly studies. On Wikipedia, expertise was most explicitly contested and most restrictively defined: the only thing that counts is technical expertise, as represented by citations to published scholarly work.

It is hardly a novel observation that the uses of technology, like the technology itself, are shaped by human meaning systems (Chandler 2000). The technical affordances 
of a communication medium do not determine what people do with it. Wikipedia provides a clear example of this. In a corpus-based factor analysis of linguistic features of Wikipedia and a similar collaborative authoring environment called Everything2, William Emigh and Susan Herring discovered that "the greater the degree of postproduction editorial control afforded by the system, the more formal and standardized the language of the collaboratively-authored documents becomes" (Emigh and Herring 2005, 1) "Paradoxically," Emigh and Herring note, "users who faithfully appropriate such systems create homogeneous entries, at odds with the goal of open-access authoring environments to create diverse content" (Emigh and Herring 2005, 1).

By the same token, however, it is important to keep in mind that there are material constraints on the possibilities for language-making. In studies of the discursive construction of standard varieties, this issue often does not arise, since it is assumed that the institutions that control this process, and the ideologies they represent, can make themselves heard. But when language-making happens in more grass-roots ways, where non-institutional sources of expertise are in play, as in the case of Pittsburghese, it is apparent that lay and institutional voices do not always have equal access to the conversational floor. At least in some cases, histories of language making may need to look beyond dominant institutional discourses about language to consider other discourses that may be in play, and to do this it may be necessary to think about the technological constraints on whose voices are heard when.

Sociolinguists and linguistic anthropologists come up against the issue of language making in a more immediately practical context when they discuss how to advocate for "endangered languages" (Hill 2002; Dorian et al. 2002), think about the 
obligations of linguists and the role of "community expertise" in dialect education projects (Rickford 1997; Wolfram, Reaser, and Vaughn 2008), or become involved in legal proceedings having to do with language (Eades 2009; Fraser 2009). In all these contexts, language expertise is up for grabs. Should linguists choose which languages need to be preserved and how to preserve them, or should community activists? How should teachers and community members be involved in designing educational materials about nonstandard varieties? Who should it be who decides whether an undocumented applicant for political asylum is really a native speaker of the language he or she claims? Thinking about the roles of linguists' expertise vis-à-vis others' is also helpful in contexts like these.

Once he came onto the scene, linguist Robert Parslow almost instantly managed to reframe local speech as a subject on which expertise was available and relevant. PreParslow articles report casual observations by almost anyone; post-Parslow articles cite expert sources. Parslow also participated in the Pittsburghese-making process in other ways. In 1979, in response to a request from a local representative of the National Association of the Holy Name Society, he prepared a "little vademecum to the local dialect" (Parslow 1979b) to be provided to people attending a Holy Name Society conference in Pittsburgh. This 10-page booklet, A Little Guide to Pittsburghese (Parslow 1979a) has as its central section a dictionary-like alphabetical vocabulary list representing local pronunciations with nonstandard spellings. Some representative entries are the following:

aht: opposite of in. "Jack Horner pooled aht his thumb," 
anymore: now (used in positive statements). "Anymore the Stillers are the best team in the Lig."

ditn't: negative of did. "Youns ditn't warsh younses hands."

jell: a prison. "Richardson designed the County Jell."

Two years later, Goodwill Industries published a booklet by Sam McCool called How to Speak Pittsburghese. McCool's book is still in print and widely available, and it has served as a model and a source for a great deal of subsequent discourse about how Pittsburghers talk. McCool had a B.A. (in English) from the University of Pittsburgh, where it is possible he took a course from Parslow and may have seen Parslow's booklet for the Holy Name Society. McCool's book looked similar enough to Parslow's booklet to make members of Parslow's family suspect that McCool had borrowed from Parslow (Patricia Parslow, personal communication), although a comparison of the two texts suggests that this is unlikely. ${ }^{11}$ The format of the definitions was exactly the same on the pittsburghese.com website, established sixteen years later.

Although not always as obviously as in Parslow's case, linguists are always part of the processes we study. We are inevitably language-makers. We are increasingly skeptical (or should be) about the traditional assumption that linguists are right and laypeople wrong about language, but we often complain about how difficult it is to get our views across to laypeople. Linguists who want to intervene in public discourse about

\footnotetext{
${ }^{11}$ While 33 of the 57 words in the Parslow list (or 57.9\%) are also in McCool's list, only $27.7 \%$ of the total items on McCool's list are defined or exemplified the same way on Parslow's list. Structurally, the two dictionaries are very similar, but Parslow and McCool could have been drawing independently on previous instantiations of this folk-dictionary genre from elsewhere. Hilliard and Wolfram (2003) describe folk dictionaries dating from the 1960s (Freeman, 1961); neither Parslow nor McCool invented the genre.
} 
language need to know how the language-making process works and decide where they stand with respect to it.

A linguist who wanted to participate in public dialect-making discourse (perhaps with an eye to finding out what laypeople know that linguists do not, perhaps to correcting misconceptions) would have found this possible in a print newspaper of the late $20^{\text {th }}$ century, although the linguist's voice would probably have been supplemented with the voices of other kinds of technical experts (language teachers, career advisors, and so on), and the popular, lay voice would be likely to frame the linguist's though headlines and illustrations. In the pittsburghese.com glossary-making activity, it would be impossible for a linguist to claim expertise. I managed to have my professional voice linked to on the site where the glossary was located only because the webmaster was sensitive to site users' confusion about the kind of expertise it represented. It would have been possible for a linguist to enter the conversation on the discussion board, where people did index the source(s) of their expertise. (Since I was not aware of the forum until the discussion was already winding down, I did not try to join the conversation.) Wikipedia, it turns out, is where a linguist would have the best chance of making his or her voice heard, due to the tight editorial constraints on acceptable sources of expertise and proper ways of indicating them.

Communication technology will continue to change, and linguists will continue to have to choose among many possibilities for getting our voices heard in discussions involving language variety. As we do this, we would benefit from realizing that we are inevitably part of the language-making process, but not always (possibly not ever) the ultimate arbiters of the (always discursively constructed) languages and dialects that 
make a difference to the people we study. Our brand of expertise is never the only one involved in the conversation. This requires thinking more reflexively than we often have about what we mean by expertise and what kinds of expertise come into play in which situations.

\section{Acknowledgments}

This project was partially funded by U.S. National Science Foundation grants BCS0417684 and BCS-0417657. Versions of this paper were presented at the American Anthropological Association's Annual Meeting and the Sociolinguistics Symposium 17, both in 2008, the University of Pittsburgh Linguistics Colloquium in 2009, and York University in 2010. I am grateful to those audiences for their questions and comments. I am also grateful to Andrew E. Danielson, who discovered the newspaper archive and made the first pass at analyzing it, to Alan Juffs, who brought my attention to the Channel 4 discussion forum, to Dan Baumgardt, who collaborated in the analysis of the online forum and in the development of the Wikipedia entry, and to Christine M. Neuwirth, who directed me to sources about new media. The Social Meaning in Language (SMiLe) reading group has, as always, been an invaluable sounding board for ideas. Anonymous readers for Language \& Communication and editor Talbot J. Taylor also made very useful suggestions. I am of course responsible for any remaining errors or confusion.

\section{References}


Agha, A. 2003. The social life of a cultural value. Language \& Communication 23: 231273.

- 2006. Language and Social Relations. Cambridge University Press, New York.

Anderson, B. 1991. Imagined Communities: Reflections on the Origin and Spread of Nationalism. Verso, London \& New York.

Baumgardt, D., Johnstone, B. 2006. Pittsburgh English. Wikipedia. http://en.wikipedia.org/wiki/Pittsburgh_English.

Berhhard, A. 1959. Pittsburgh speech has its own differences. Pittsburgh Post-Gazette, December 4, p. 2.

Bhatt, R. M. 2002. Experts, dialects, and discourse. International Journal of Applied Linguistics 12 (1): 74-109.

Blommaert, Jan. 2008. Artefactual ideologies and the textual production of African languages. Language \& Communication 28: 291-307.

Bloom, S. 1977. Everyone talks funny but us. The Pittsburgher, pp. 39, 79.

Braknis, G. 1991. Straight talk: Slang can derail job interview, stifle career. Pittsburgh press, December 3, sec. B, pp. 1, 3.

Browne, J. 1976. Our towne. Pittsburgh Post-Gazette, December 20, sec. B, p. 1.

Bryant, S. L., Forte, A., Bruckman, A. 2005. Becoming Wikipedian: Transformation of participation in a collaborative online encyclopedia. In: Proceedings of GROUP '05, Sannibel Island, FL. Association for computational machinery. Pp.1-10.

Cameron, D. 1995. Verbal Hygiene. Routledge, London \& New York.

Chandler, D. 2000. Technological or media determinism. University of Aberdeen. http://www.aber.ac.uk/media/Documents/tecdet/tecdet.html. 
Charney, D. 2003. Lone geniuses in popular science: The devaluation of scientific consensus. Written Communication 20: 215-241.

Crozier, A. 1984. The Scotch-Irish influence on American English. American Speech 59: $310-31$.

Danielson, A. E. 2001. Talking about Pittsburgh speech: Representations of 'local' speech features in Pittsburgh's print media. Term paper. Carnegie Mellon University.

Davidson, J. 1984. We'uns sure stretch the King's English. Pittsburgh Press, December 30, Sunday Magazine, p. 4.

Dorian, N.C., England, N. C., Fishman, J. A., Hinton, L. 2002. Commentary. Journal of Linguistic Anthropology 12(2): 134-156.

Downes, E. J., McMillan, S. J. 2000. Defining interactivity: A qualitative identification of key dimensions. New Media \& Society 2(2): 157-179.

Dressman, M. 1979. Redd up. American Speech 54: 141-145.

Dunaway, W. F. 1944. The Scotch-Irish of Colonial Pennsylvania. Chapel Hill, Chapel Hill.

Eades, D. 2009. Testing the claims of asylum seekers: The role of language analysis. Language Assessment Quarterly 6(1): 30-40.

Eberhardt, M.. 2009. The sociolinguistics of ethnicity in Pittsburgh. Language and Linguistics Compass 3(6): 1443-1454.

Emigh, W., Herring, S. 2005. Collaborative authoring on the web: A genre analysis of online encyclopedias. In: Proceedings of the Thirty-Eighth Hawai'i International Conference on System Sciences (HICSS-38). Los Alamitos: IEEE Press. http://ella.slis.indiana.edu/ herring/wiki.pdf. 
Fleming, A. 2008. History: Yinz can learn about Pittsburghese online - Podcasts provide origins of the city's most colorful words. Pittsburgh City Paper. January. http://www.pittsburghcitypaper.ws/gyrobase/Content?oid=oid\%3A41403.

Fraser, H. 2009. The role of 'educated native speakers' in providing language analysis for the determination of the origin of asylum seekers. The International Journal of Speech,Language and the Law 16(1): 113-138.

Gal, S., Irvine, J. T. 1995. The boundaries of languages and disciplines: How ideologies construct difference. Social Research 62: 967-1001.

Gitman, M. 1997. Internet 'n' at: Web site pools the finer points of Pittsburghese. Pittsburgh Post-Gazette, January 20, sec. D, pp. 1, 2.

Gleason, D.. 1965. What's that you said. Pittsburgh Press, May 30, Sunday Magazine, p. 4.

—. 1967. Strictly Pittsburghese: Only in Western Pennsylvania do you hear 'gum band' and 'needs washed'. Pittsburgh Press, June 18, Sunday Magazine, p. 3.

Gray, J. 1968. Dialect in dilemma. Pittsburgh Press, July 14, Family Magazine (page number illegible).

Harris, R. 1980. The Language-makers. Cornell University Press, Ithaca, NY.

— 1981. The Language Myth. New York: St. Martin's Press, New York.

—. 1987. The Language Machine. Cornell University Press, Ithaca, NY.

Heritage, J., Raymond, G. 2005. The terms of agreement: Indexing epistemic authority and subordination in talk-in-interaction. Social Psychology Quarterly 68(1): 1538.

Hermann, J. 2008. The 'language' problem. Language \& Communication 28: 93-99. 
Herring, S.C. 2007. A faceted classification scheme for computer-mediated discourse. Language@Internet 1. http://www.languageatinternet.de/articles/2007/761/index_html/.

Hill, J.H. 1995. Junk Spansh, covert racism, and the (leaky) boundary between public and private spheres. Pragmatics 5: 197-212.

_. 2002. "Expert rhetorics" in advocacy for endangered languages: Who is listening, and what do they hear? Journal of Linguistic Anthropology 12(2): 119133.

Hilliard, S., Wolfram, W.. 2003. The sociolinguistic significance of folk dictionaries. Paper presented at the Southeastern Conference on Linguistics. Washington D.C.

Hopper, P. J. 1988. Emergent grammar and the a priori grammar postulate. In: Tannen, D. (Ed.), Linguistics in Context: Connecting Observation and Understanding. Ablex, Norwood, NJ, pp. 117-134.

Huzinec, M. 1978. Pitt prof finds Pittsburghese a slippy subject. Pittsburgh Press, November 21, sec. A, p. 2.

Irvine, J. T. 1995. The family romance of colonial linguistics: Gender and family in nineteenth-century representations of African languages. Pragmatics 5: 139-153.

- 2008. Subjected words: African linguistics and the colonial encounter. Language \& Communication 28 (4): 323-343.

- 2009. Stance in a colonial encounter: How Mr. Taylor lost his footing. In: Jaffe, A. (Ed.), Sociolinguistic Perspectives on Stance. Oxford University Press, Oxford, New York, pp. 53-72.

Jensen, J. F. 1999. "Interactivity" -- Tracking a new concept in media and communication 
studies. In: Mayer, P. A. (Ed.), Computer Media and Communication: A Reader. Oxford University Press, Oxford, pp. 160-187.

Johnstone, B., Andrus, J., Danielson, A. E.. 2006. Mobility, indexicality, and the enregisterment of "Pittsburghese". Journal of English Linguistics 34(2): 77-104.

Johnstone, B., Baumgardt, D. 2004. "Pittsburghese" online: Vernacular norming in conversation. American Speech 79: 115-145.

Johnstone, B., Danielson, A. E. 2001. "Pittsburghese" in the daily papers, 1910-2001: Historical sources of ideology about variation. Paper presented at New Ways of Analyzing Variation 33, Raleigh, NC.

Johnstone, B., Kiesling, S. F. 2008. Indexicality and experience: Exploring the meanings of /aw/-monophthongization in Pittsburgh. Journal of Sociolinguistics 12(1): 5-33.

Kiesling, S. F., Wisnosky, M. 2003. Competing norms, heritage prestige, and /aw/-monophthongization in Pittsburgh. Poster presented at New Ways of Analyzing Variation 32 . Philadelphia, PA.

Kloman, H. 1992. The truth and consequences of Pittsburghese: How you say downtown can affect your career. Pittsburgh Magazine, February, pp. 40-43.

Knox, D.. 2001. Doing the Doric: The institutionalization of regional language and culture in the north-east of Scotland. Social \& Cultural Geography 2 (3): 315-331.

Kurath, H., McDavid, R. I. 1961. The Pronunciation of English in the Atlantic States: Based upon the Collections of the Linguistic Atlas of the Eastern United States. University of Michigan Press, Ann Arbor.

Labov, W. 2001. Principles of Linguistic Change: Social Factors. Blackwell, Malden, MA, Oxford, UK. 
Labov, W., Ash, S., Boberg, C.. 2005. Atlas of North American English: Phonetics, Phonology and Sound Change. Mouton/deGruyter, Berlin, New York.

Leo, P.. 1982. This column needs read. Pittsburgh Post-Gazette, June 21, sec. A, p. 4.

Lister, M., Dovey, J., Giddings, S., Grant, I., Kelly, K. 2009. New Media: A Critical Introduction. 2nd ed. Routledge, London.

Love, G. 1952. What we say. Pittsburgh Press, January 18, sec. 2, p. 23.

Love, N. 2009. Science, language and linguistic culture. Language \& Communication 29: 26-46.

McCool, S.. 1982. Sam McCool's New Pittsburghese: How to Speak Like a Pittsburgher. Hayford Press, Pittsburgh PA.

McGough, M.. 1973. Pittsburghers have a dialect all their own. Pittsburgh Post-Gazette, October 15, Daily Magazine, p. 22.

McHugh, R. 1979. He scotches Pittsburgh monopoly on "yunz". Pittsburgh Press, sec. A, p. 2.

McMillan, S. J. 2002. Exploring models of interactivity from multiple research traditions: Users, documents, and systems. In: Lievrouw, L., Livingstone, S. (Eds.), Handbook of New Media: Social Shaping and Consequences of ICTs. Sage Publications, Thousand Oaks, CA, pp. 163-182.

Milroy, J., Milroy, L. 1985. Authority in Language: Investigating Language Prescription and Standardization. Routledge and Kegan Paul, London \& New York.

Montgomery, M.. 1989. Exploring the roots of Appalachian English. English WorldWide 10: 227-278.

- 2000. British and Irish Antecedents. In: Algeo, J. (Ed.), English in North 
America. Cambridge \& New York: Cambridge University Press, Cambridge \& New York, pp. 86-153.

- 2002. The structural history of $y^{\prime}$ all, you all, and you'uns. Southern Journal of Linguistics 26 (1): 19-27.

Montgomery, M., Kirk, J. M.. 2001. "My mother, whenever she passed away, she had pneumonia": The history and functions of whenever. Journal of English Linguistics 29(3): 243-249.

Ove, T. 1998. Pals send tape n'at to priest in Rome. Pittsburgh Post-Gazette, January 19, sec. B, pp. 1, 2.

Parslow, R.. 1979a. The Pittsburgh Diocesan Holy Name Society Presents a Little Guide to Pittsburghese. Pittsburgh Diocesan Holy Name Society, Pittsburgh PA.

_ 1979b. Letter to John H. Farmerie. May 4.

Pentzold, C. 2007. Fixing the floating gap: The online encyclopaedia Wikipedia as a global memory place. Paper presented at the Centre for the Study of Global Governance, London School of Economics, June 17. http://www.lse.ac.uk/Depts/global/EventsPDFs/MemoryWorkshop/FixingtheFloat ingGap_ Pentzold.pdf.

Petrucelli, A.W. 2008. A fresh look: Speaking clearly in Pittsburghese. Pittsburgh PostGazette, December 1, Living. http://www.post-gazette.com/pg/08336/93148251.stm\#ixzz0wOodb9UL.

Raymond, G. 2000. The voice of authority: the local accomplishment of authoritative discourse in live news broadcasts. Discourse Studies 2(3): 354-379.

Rickford, J. R. 1997. Unequal partnership: Sociolinguistics and the African American 
speech community. Language in Society 26: 161-197.

Ronkin, M., Karn, H. E.. 1999. Mock Ebonics: Linguistic racism in parodies of Ebonics on the internet. Journal of Sociolinguistics 3: 360-380.

Schieffelin, B. B., Woolard, K. A, Kroskrity, P. V., eds. 1988. Language Ideologies: Practice and Theory. Oxford University Press, New York.

Silverstein, M. 1993. Metapragmatic discourse and metapragmatic function. In: Lucy, J. A. (Ed.) Reflexive Language. Cambridge University Press, Cambridge, pp. 33-58. Swetnam, G. 1959a. Pittsburgh's peculiar proverbs. Pittsburgh Press, March 8, Sunday Magazine, p. 3.

— 1959b. Pittsburgh patois. Pittsburgh Press, September 6, Sunday Magazine, pp. 4-5.

— 1972. Your talk tells tales. Pittsburgh Post-Gazette, October 15, Sunday Magazine, pp. 10-11.

Voice of America. Pittsburghese. MP3. VOA Wordmaster. http://www.unsv.com/voanews/wordmaster/scripts/2009/09/22/.

Warnick, M. S. 1990. Lawrenceville aside, fewer of yunz speak Pittsburghese. Pittsburgh Press, July 15, sec. H, pp. 1, 4.

Wolfram, W., Reaser, J., Vaughn, C. 2008. Operationalizing linguistic gratuity: From principle to practice. Language and Linguistics Compass 2(6): 1109-1134.

Woolard, K. A., Schieffelin, B. B. 1994. Language ideology. Annual Review of Anthropology 23: 55-82.

Zelinsky, W. 1980. North America's vernacular regions. Annals of the Association of American Geographers 70: 1-16. 
